Flash co-pyrolysis of biomass with polylactic acid. Part 1: Influence on bio-oil yield and heating value

Non Peer-reviewed author version

CORNELISSEN, Tom; YPERMAN, Jan; REGGERS, Guy; SCHREURS, Sonja \& CARLEER, Robert (2008) Flash co-pyrolysis of biomass with polylactic acid. Part 1: Influence on bio-oil yield and heating value. In: FUEL, 87(7). p. 1031-1041.

DOI: 10.1016/j.fuel.2007.07.019

Handle: http://hdl.handle.net/1942/8268 


\title{
Flash co-pyrolysis of biomass with polylactic acid part 1. Influence on bio-oil yield and heating value
}

\author{
T. Cornelissen 1 , J. Yperman 1, , G. Reggers ${ }^{1}$, S. Schreurs ${ }^{2}$ and R. Carleer ${ }^{1}$ \\ 1. Lab of Applied Chemistry, CMK, Hasselt University, Agoralaan Gebouw D, 3590 Diepenbeek, Belgium. \\ 2. NuTec, department IWT, XIOS, Agoralaan Gebouw H, 3590 Diepenbeek, Belgium.
}

\begin{abstract}
High amounts of water present in bio-oil are one of the major drawbacks for its utilisation as a fuel. One technology that shows the potential to satisfy the demand for bio-oil with a reduced water content is the flash co-pyrolysis of biomass with polylactic acid, PLA. The influence of PLA on the pyrolysis of willow is investigated with a semi-continuous home-built pyrolysis reactor. Flash co-pyrolysis of willow/PLA blends $(10: 1,3: 1,1: 1$ and 1:2) show synergetic interaction. A higher bio-oil yield and a lower water content as a function of the willow/PLA ratios are obtained. Among the tested blends, the 1:2 willow/PLA blend shows the most pronounced synergy: a reduction in the production of pyrolytic water of almost 28 $\%$, accompanied by an increase of more than $37 \%$ in the production of water-free bio-oil. Additionally, PLA shows to have a positive influence on the energetic value of the bio-oil produced and on the resulting energy recuperation.
\end{abstract}

Key words: flash co-pyrolysis; willow; polylactic acid; pyrolytic water; bio-oil.

* Corresponding author. Tel: +32 11268 320; Fax: +32 11268301.

E-mail address: jan.yperman@uhasselt.be 


\section{Introduction}

Global Warming, the Kyoto Protocol, the emission of greenhouse gases and the depletion of fossil fuels are the topics of environmental pleadings worldwide. The development of new and renewable energy sources (including biofuels) is the key to change [1]. The flash pyrolysis of biomass is a promising route with regard to the production of solid (char), liquid (bio-oil) and gaseous materials as possible alternate energy sources [2-4]. In order to maximise the bio-oil yield, process conditions should be: low temperature, high heating rate and short gas residence time $[5,6]$. Today, bio-oil can substitute fuel oil or diesel in many static applications including boilers, furnaces, engines and turbines used for electricity generation. Additionally, it can be upgraded to transportation fuels [7] and even to chemicals with added value.

The flash pyrolysis of biomass inherently results in the production of pyrolytic water, which is one of the major drawbacks of the bio-oil produced. Nevertheless, the presence of water has both positive and negative effects on the bio-oil properties [5, 8]. It improves bio-oil flow characteristics, which is beneficial for combustion. Moreover, it leads to a more uniform temperature profile in the cylinder of a diesel engine and to lower $\mathrm{NO}_{\mathrm{x}}$ emissions. On the other hand, it lowers the heating value and flame temperature of the bio-oil. It also contributes to the increase in ignition delay and in some cases to the decrease of combustion rate as compared to diesel fuels. The reduction of the water content is one of the few required but essential upgrading steps in order to increase the applicability of bio-oil and to make the production of bio-oil competitive. Oasmaa summarised the requirements of bio-oil set by Ensyn (a liquid producer), Wärtsilä (an engine manufacturer) and Birka (a potential bio-oil user). Here, the maximum water content was defined as $25-26$ wt. \% [9], while literature reports a water content between $15-30 \%$ and even more [6, 8].

To our knowledge, the flash pyrolysis of willow has not been investigated extensively yet. Ingemarsson studied the slow pyrolysis of willow and analysed the compounds produced using gas chromatographic 
methods [10]. Mészáros et al. performed TG/MS analysis of willow and other young wood samples in order to obtain information on their thermal behaviour [11]. Prins et al. specifically addressed the decomposition of hemicellulose of willow in the relatively low temperature range of $498-573 \mathrm{~K}$, a process also known as torrefaction $[12,13]$.

The use of co-pyrolytic techniques on biomass/plastic ratios has already been investigated [14-17]. One of the most important parameters for liquid production is the ratio in the feedstock.

Polylactic acid, PLA, is a biologically degradable polymer and is produced principally via microbial fermentation of sugar feedstock [18]. PLA is possibly the most commonly applied biopolymer and has the most potential for widespread use, but does not have the best biodegradability properties amongst biopolymers. Therefore, co-pyrolysis of PLA and biomass (willow) offers an alternative waste treatment option and may act as an upgrading step during the pyrolysis of willow. The thermal decomposition of PLA has already been studied in detail [19-22].

The goal of the present research is to reduce the amount of pyrolytic water by flash co-pyrolysis of willow and PLA. Therefore, the co-pyrolytic behaviour of the willow/PLA blends are investigated with a semi-continuous home-built pyrolysis reactor. In this paper, the influence of PLA and willow on the biooil yield, its water content and heating value during flash co-pyrolysis will be discussed.

\section{Experimental}

\subsection{Materials}

The experiments are performed on willow - Salix, PLA and willow/PLA blends. The willow branches (the leaves are not taken into account in this study) are cut and dried at room temperature before being shredded into small particles $(\sim 2 \mathrm{~mm})$. A particle size of $<2 \mathrm{~mm}$ guarantees a fast inner-heating rate during pyrolysis and thus ensures a flash pyrolysis of the entire particle. 
The experiments on willow/PLA blends with a w/w ratio of 10:1, 3:1, 1:1 and 1:2 are investigated and compared with the results obtained for 100\% willow and 100\% PLA (reference samples 1 and 2, respectively) to evaluate the effects on the bio-oil yield, its water content and its calorific value.

2.2. Explorative analysis of pure biomass and PLA

Ultimate Analysis

The CHNS- and O-content of the input materials are determined via two distinct experiments, using a FlashEA 1112 Elemental Analyser of Thermo Electron Corporation. Approximately 2 - $4 \mathrm{mg}$ of sample is introduced into a container, which is injected by an autosampler. In case of CHNS-determinations, 5 $10 \mathrm{mg}$ vanadiumpentoxide is added to the sample as a combustion catalyst. 2,5-Bis(5-tert-butylbenzoxazol-2-yl)thiophene (BBOT) and L-cystine are used as standards for the CHNS- and Odeterminations, respectively.

Thermogravimetric analysis - TGA

About $30 \mathrm{mg}$ of sample is pyrolysed under approximately $35 \mathrm{ml} / \mathrm{min} \mathrm{N}_{2}$ flow at a heating rate of $10 \mathrm{~K} / \mathrm{min}$ from room temperature (RT) to $973 \mathrm{~K}$ with a DuPont Instruments 951 Thermogravimetric Analyzer.

Thermogravimetric/Mass spectrometric analysis - TG/MS

A Hi-Res TGA 2950 Thermogravimetric Analyzer of TA Instruments is connected with a Pfeiffer Vacuum ThermoStar mass spectrometer. Approximately $1-2 \mathrm{mg}$ of sample is pyrolysed under a Helium flow of $100 \mathrm{ml} / \mathrm{min}$ at a heating rate of $20 \mathrm{~K} / \mathrm{min}$ from RT to $873 \mathrm{~K}$. The mass spectrometer is set at the standard ionising voltage of $70 \mathrm{eV}$ with a mass range $\mathrm{m} / \mathrm{z}$ of $5-255$ and a scan rate of $5 \mathrm{scans} / \mathrm{min}$. 
Thermogravimetric/Fourier Transform - Infrared analysis - TG/FTIR

A DuPont Instruments 951 Thermogravimetric Analyzer, interfaced (at $473 \mathrm{~K}$ ) with a gas cell, and coupled with a Bruker Vertex 70 FT-IR spectrometer (resolution: $4 \mathrm{~cm}^{-1}$ ) is applied. Approximately 20 $\mathrm{mg}$ of sample is pyrolysed at a heating rate of $20 \mathrm{~K} / \mathrm{min}$ from $\mathrm{RT}$ to $873 \mathrm{~K}$ under a constant Helium flow of $100 \mathrm{ml} / \mathrm{min}$.

\subsection{Flash Pyrolysis}

\section{Experimental flash pyrolysis set-up}

The semi-continuous home-built pyrolysis reactor $(360 \mathrm{~mm}$ high with a diameter of $88 \mathrm{~mm}$ ), Fig. 1 (part a), is manufactured in stainless steel (AISI 304). Within the reactor, a heat transfer medium (white sand, $\pm 700 \mathrm{~g}$ or $450 \mathrm{ml}$ ) is inserted. Before use, this sand is dried at $383 \mathrm{~K}$ to ensure that all water is removed. Preliminary, the sand is pre-treated in batch at $873 \mathrm{~K}$ to remove all impurities. During the entire process, the sand is in constant motion with the aid of an Archimedical screw, ensuring a homogeneous temperature sand bed operating system. This Archimedical screw also serves as a gas inlet system. The reactor (and the sand) is heated by a tailored heating jacket (Horst GmbH, Lorsch, Germany).

The injection system, Fig. 1 (part b), is manufactured in stainless steel (AISI 304) as well. It consists of a reservoir with a volume of $600 \mathrm{ml}$ and an injector. The injector is a hollow tube linking the reservoir, which contains the biomass, with the reactor. Via this tube, the biomass is transported into the reactor by means of a second Archimedical screw with a controlled feeding rate $(1-120 \mathrm{rpm})$. A second gas inlet is situated inbetween the biomass container and the injector.

The recuperation system, Fig. 1 (part c), is a stainless steel (AISI 304) collector vessel with a volume of $580 \mathrm{ml}$ and is kept at room temperature. Inbetween the reactor and the collector, a small water cooler is constructed to quench the gases. On top of the collector vessel, a cold trap made out of copper (kept at 
$77 \mathrm{~K}$ with liquid nitrogen) is installed to collect all condensable gases. The non-condensable gases exit the recuperation system via the chimney into a fume hood.

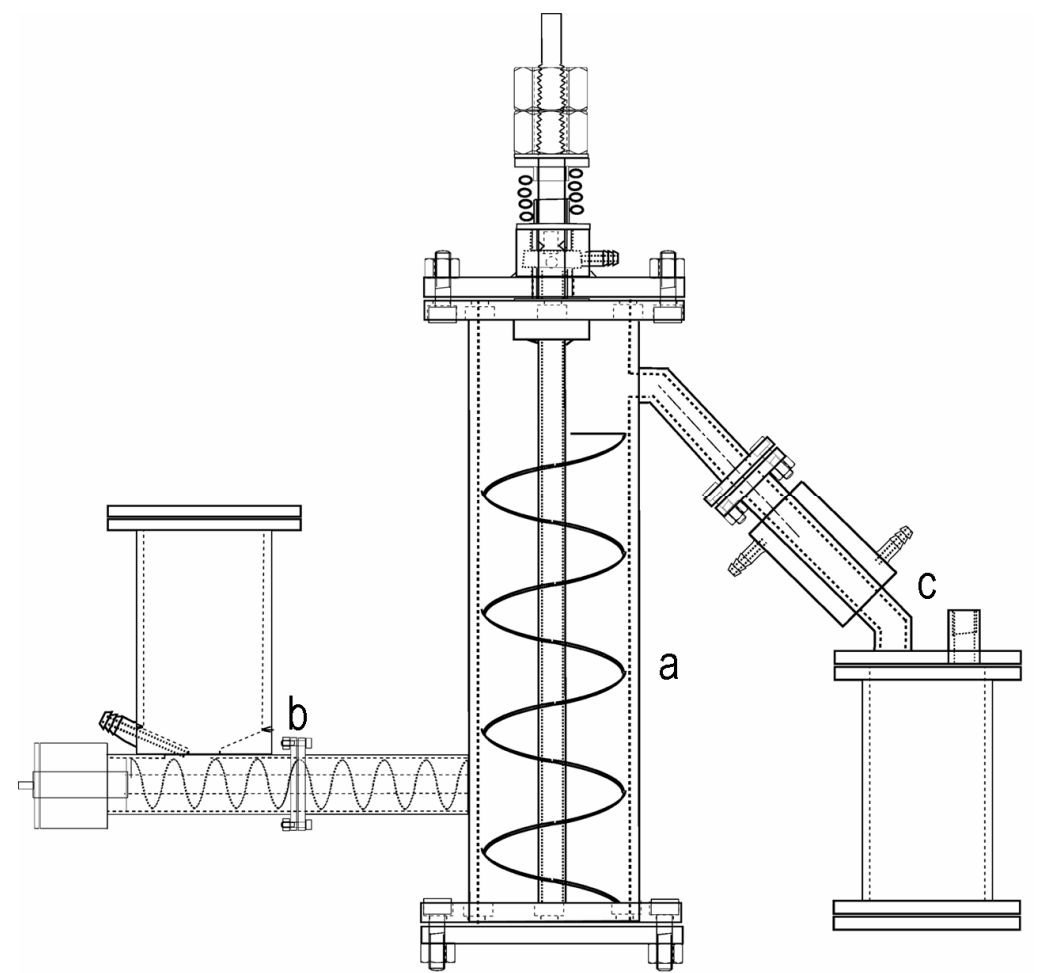

Figure 1: Pyrolysis set-up: a, reactor (at PT in $\mathrm{K}$ ); b, injection system (at RT in $\mathrm{K}$ ) with a biomass reservoir; and c, recuperation system (at $\mathrm{RT}$ in $\mathrm{K}$ ) with an additional water cooler.

\section{Procedure}

Preliminary, all materials ( $\pm 700 \mathrm{~g}$ sand and $\pm 100 \mathrm{~g}$ input) are dried at $383 \mathrm{~K}$. When heating has started, nitrogen gas continuously enters the reactor via two ways to guarantee an "oxygen-free" environment: firstly, via the hollow shaft of the Archimedical screw in the reactor which also acts as a gas pre-heater $(70 \mathrm{~m} / \mathrm{min})$, and secondly via the injection system $(70 \mathrm{~m} / / \mathrm{min})$. As soon as the sand inside the reactor reaches the pyrolysis temperature (PT), the nitrogen flow is stopped and the injection system is started; inserting the willow, PLA or willow/PLA blend into the reactor at a rate of $20 \mathrm{rpm}$, which is, at the moment, the optimal speed for the material in question. In this way, an injection rate of approximately $140 \mathrm{ml}$ per minute is achieved. The willow, PLA or willow/PLA blend subsequently undergoes a flash pyrolysis and is converted into volatiles which mainly condense into the recuperation system as bio-oil. 
During the entire experiment (heating, injection, pyrolysis,...), temperature measurements are taken at the top of the sand bed with a thermocouple type K.

\subsection{Water content and heating value of bio-oil}

\section{Water content}

The water content of the different bio-oil samples, containing a high percentage of water, is measured using the Dean-Stark method. Around 5 to $10 \mathrm{ml}$ bio-oil is introduced into a $250 \mathrm{ml}$ flask together with approximately $60 \mathrm{ml}$ toluene. Water is separated from the bio-oil in azeotropic conditions into a calibrated reservoir, indicating the amount of water present in the bio-oil.

Bio-oils with very low water content are analysed by means of a Karl-Fisher titration. A SCHOTT, equipped with a TR85 detector, a 180/10 full-automatic burette and a TM120 reaction vessel, is used. Here, experiments are performed on $0.5 \mathrm{ml}$ bio-oil.

\section{Calorimetry}

The samples (approximately $1 \mathrm{~g}$ ) are analysed with an IKA C5003 control calorimeter equipped with an IKA KV 600 Digital water cooler and a Sartorius CP224S analytical balance. Oxygen is connected to the system to pressurise the bomb. Measurements are executed in dynamic mode and the calibration of the system is performed with benzoic acid (palleted, C723) of IKA with a higher heating value (H.H.V.) of $26460 \mathrm{~J} / \mathrm{g}$ (relative standard deviation of $0.01 \%$ ).

\section{Results and discussion}

The main characteristics of willow and PLA are listed in Table 1. Based on the ultimate analysis, both materials have a high $\mathrm{C}$ - and $\mathrm{O}$-content, and a low $\mathrm{H}$-content. No $\mathrm{S}$ is detected and the $\mathrm{N}$-content is 
very low. Their calorific values have been measured as well and are within the same range, around $19000 \mathrm{~J} / \mathrm{g}$.

Table 1: Main characteristics (on dry basis) of willow and PLA.

\begin{tabular}{lcc} 
Characteristics & Willow & $\underline{\underline{\text { PLA }}}$ \\
\hline \hline Proximate analysis (\%) & & \\
Moisture & 3.24 & 0.00 \\
Volatile & 74.66 & 98.05 \\
Fixed C & 20.39 & 1.30 \\
Ash & 1.71 & 0.65 \\
\hline \hline Ultimate analysis (\%) & & \\
Carbon & 46.91 & 49.84 \\
Hydrogen & 5.95 & 5.63 \\
Nitrogen & 0.63 & 0.15 \\
Oxygen & 41.69 & 44.42 \\
H/C molar ratio & 1.52 & 1.36 \\
O/C molar ratio & 0.67 & 0.67 \\
\hline \hline Calorific value $(\mathrm{J} / \mathrm{g})$ & & \\
Calorimetric analysis & 19088 & 18597 \\
\hline \hline
\end{tabular}

TGA is executed to obtain an overview of the basic characteristics (Table 1) and insight in the pyrolysis behaviour of willow, PLA and their blends. For the pyrolysis of the pure materials and the 1:2 blend, the mass loss curves and the derivatives are shown in Figure 2. The thermogram of willow points out that willow contains more than $3 \%$ moisture, while for PLA a negligible amount is measured.

Willow, a woody biomass, mainly consists of the three basic constituents of wood: cellulose, hemicellullose and lignine. It is known that lignin decomposes within a wide temperature interval (433-1173 K) and its DTG peak is not commonly distinguishable $[11,12,23]$. Hemicellulose (the shoulder in the profile of Fig. 2a) is the second constituent to decompose, followed by cellulose (the main DTG peak centered around $626 \mathrm{~K}$ ), which decomposes in a narrow temperature interval from about 473 up to 673 $\mathrm{K}$. This is the interval in which the main decomposition takes place and which accounts for the greatest mass loss during the biomass pyrolysis process $[11,12,23]$. PLA on the other hand (Fig. 2b) decomposes in one single and narrow temperature interval that ranges from 563 to $663 \mathrm{~K}$, with a maximum at $632 \mathrm{~K}$. Important to note is that the maximum decomposition temperature of willow and PLA coincide. 

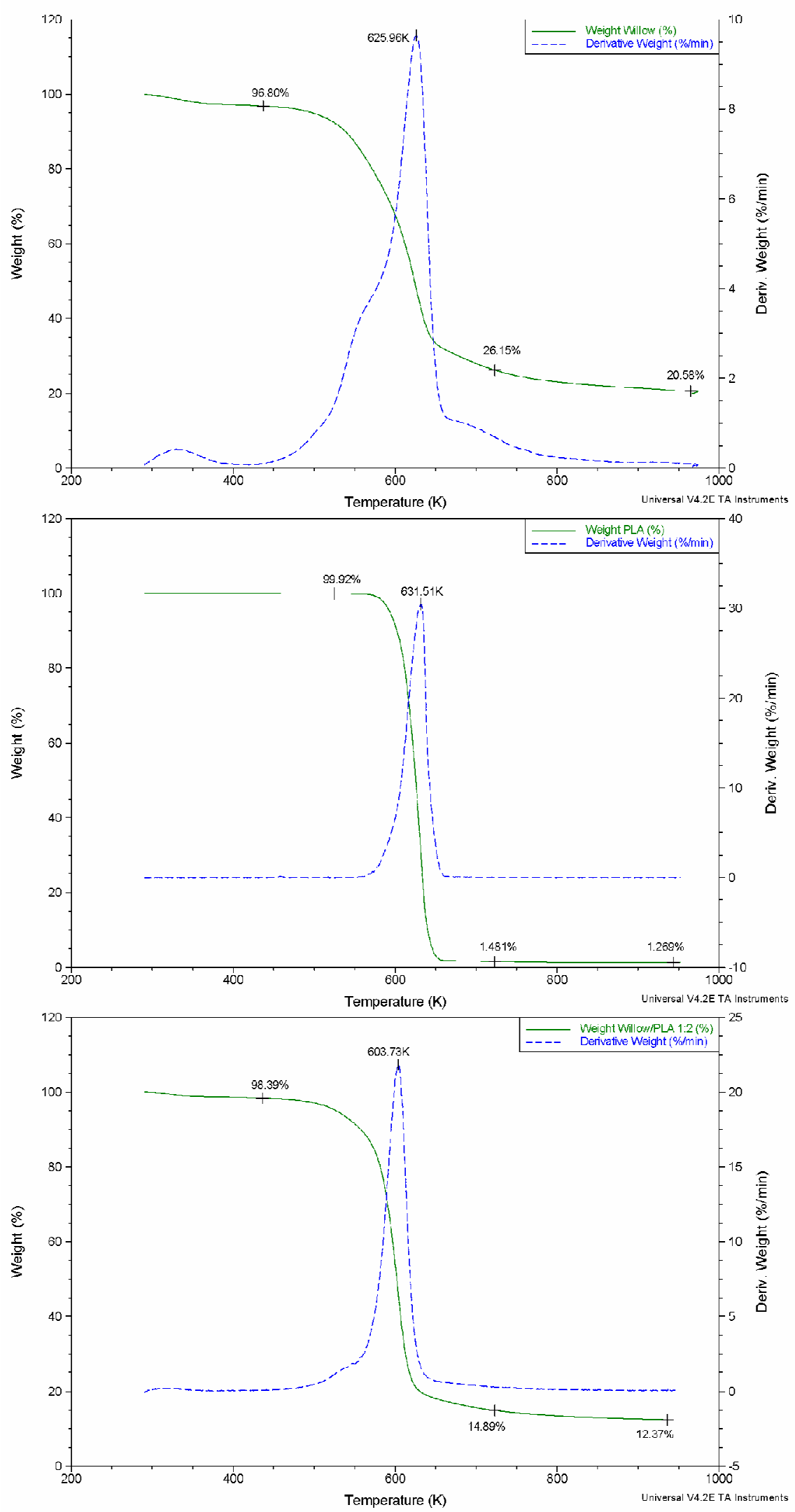

Figure 2: Weight loss and their derivatives of a, willow; b, PLA; and c, 1:2 willow/PLA, obtained by TGA. 
The triple stage decomposition of willow is observed in all blends, however, in reduced form directly correlated with the addition of PLA. The thermogram of the 1:2 willow/PLA blend gives a profile that is very comparable to that of pure PLA (Fig. 2c). The peak maxima of the derivatives of the pure materials and their blends ranges between $603 \mathrm{~K}$ and $633 \mathrm{~K}$. Figure 2 also shows that most of the decomposition reactions are finalised at a temperature of about $673 \mathrm{~K}$, justifying a maximum flash pyrolysis temperature of $723 \mathrm{~K}$ during the semi-continuous pyrolysis experiments.

Based on the TG/MS ion-kinetograms of $\mathrm{m} / \mathrm{z} 18$ (Figure 3), it can be concluded that pyrolytic water is formed during the intense decomposition at the temperature range between 473 and $673 \mathrm{~K}$. More specifically, the pattern of the DTG-curves in the thermogram (Fig. 2) are also visible for the evolution of mass '18' (water) in function of time during the pyrolysis of willow, PLA, and their blends (Fig. 3). A difference in the amount of pyrolytic water produced from pure willow (1 $\mathrm{g}$ of starting material) and pure PLA (also $1 \mathrm{~g}$ of starting material) is observed, predicting a high and a low water content for willow and PLA bio-oil, respectively. Additionally, an intermediate production of pyrolytic water for the $1: 2$ willow/PLA blend ( $2 \mathrm{~g}$ of starting material) is indicated.

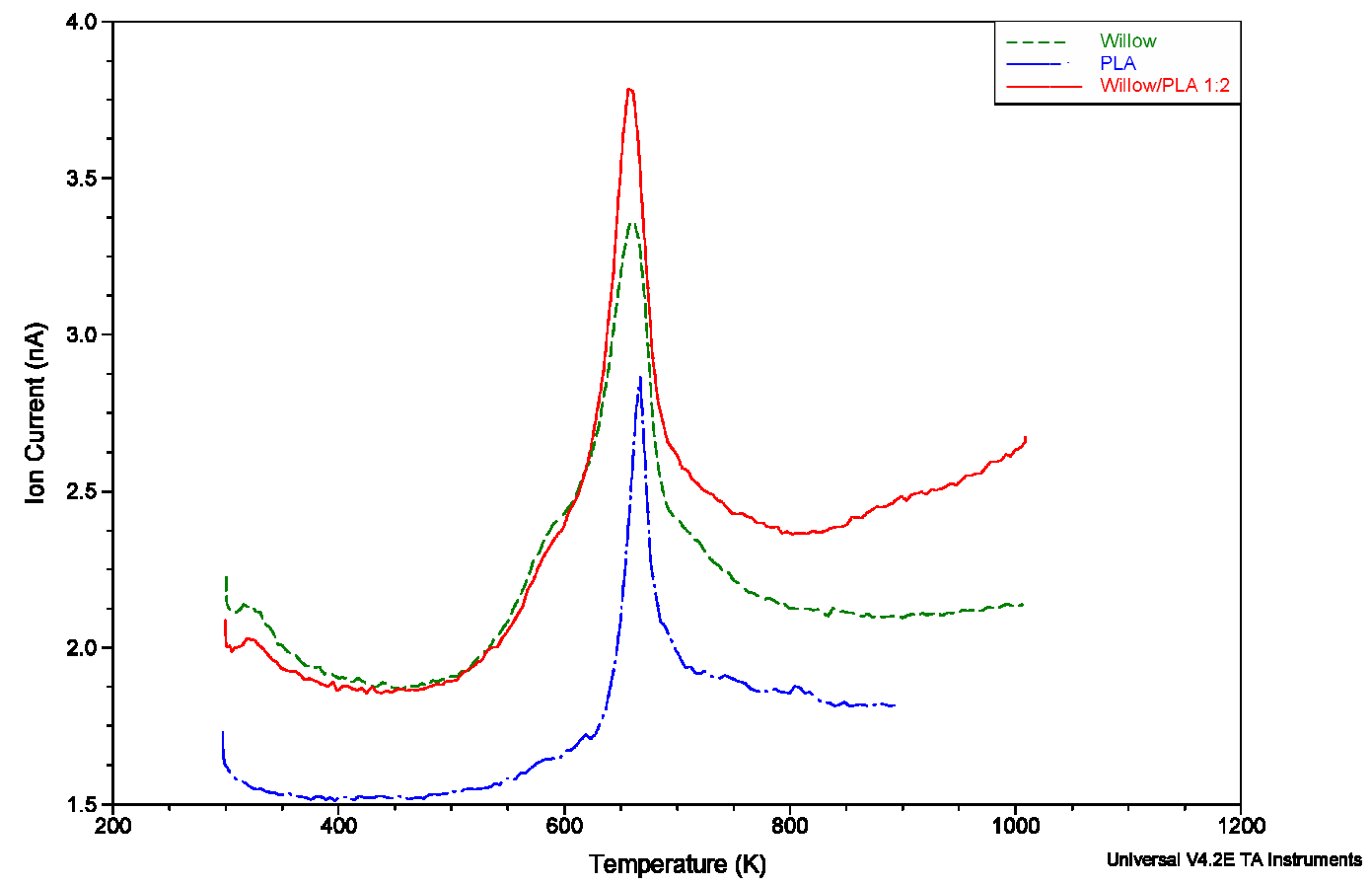

Figure 3: Evolution of mass ' 18 ' in function of temperature (= ion-kinetogram of $m / z$ 18) for willow, PLA, and 1:2 willow/PLA, obtained by TG/MS. 
Other masses, e.g. $\mathrm{m} / \mathrm{z} 16,28,29,44,45$, and 46; potentially representing the release of methane, carbon monoxide, aldehydes and/or ketones, carbon dioxide, alcohols and/or ethers, and acids respectively, have additionally been detected by means of TG/MS. Here, no extra conclusions could be drawn besides the fact that the evolution of the ion-kinetograms resembles the pyrolysis DTG-curves, as is shown for water in Figure 3.

TG/FTIR analysis shows some other interesting evolutions during co-pyrolysis. For comparison, the FTIR spectra extracted at the highest pyrolysis decomposition rate $(T=603-633 \mathrm{~K})$ are visualised in Figure 4. First, a shift in the most abundant band at $1650-1860 \mathrm{~cm}^{-1}$, which represents the carbonyl functionalities, is observed. Here, a shift of band position towards a higher wavenumber is shown: 1745 $\mathrm{cm}^{-1}$ for willow, $1766 \mathrm{~cm}^{-1}$ for PLA and $1793 \mathrm{~cm}^{-1}$ for $1: 2$ willow/PLA. Additionally, an intense peak at $1200-1250 \mathrm{~cm}^{-1}$ for $1: 2$ willow/PLA is formed and cannot be explained by the reference materials according to the applied ratio. Finally, the ratio between the $\mathrm{CO}$ and the $\mathrm{CO}_{2}$ bands for willow, PLA and 1:2 willow/PLA varies (Fig. 4): in the case of PLA, the CO band $\left(2000-2200 \mathrm{~cm}^{-1}\right)$ is larger compared with the $\mathrm{CO}_{2}$ band $\left(2300-2400 \mathrm{~cm}^{-1}\right)$, while the $\mathrm{CO}$ band is clearly less intense for willow and for $1: 2$ willow/PLA compared with their $\mathrm{CO}_{2}$ band, although the 1:2 blend is dominated by PLA. Such differences in pattern can only be explained by additional reactions occurring during co-pyrolysis, resulting in an altered gas composition (both condensable and non-condensable). Figure 5 shows the evolution of $\mathrm{CO}$ and $\mathrm{CO}_{2}$ during the thermal decomposition of willow, PLA and 1:2 willow/PLA in more detail. The response for $\mathrm{CO}_{2}$ between 473 and $623 \mathrm{~K}$ varies in importance relative to the maximum decomposition temperature (> $623 \mathrm{~K}$ ): PLA shows almost no response before $623 \mathrm{~K}$, while willow shows an important shoulder in this temperature interval. Even though the proportion between $\mathrm{CO}$ and $\mathrm{CO}_{2}$ of the 1:2 blend resembles willow the most $\left(\mathrm{CO}_{2} \gg \mathrm{CO}\right)$, the evolution of $\mathrm{CO}_{2}$ obviously differs from that of willow showing only a negligible shoulder between 473 and $623 \mathrm{~K}$. This indicates that another degradation mechanism takes place and confirms the occurrence of additional reactions during co- 
pyrolysis. It seems that the degradation of 1:2 willow/PLA is shifted towards higher temperatures in comparison with pure willow.
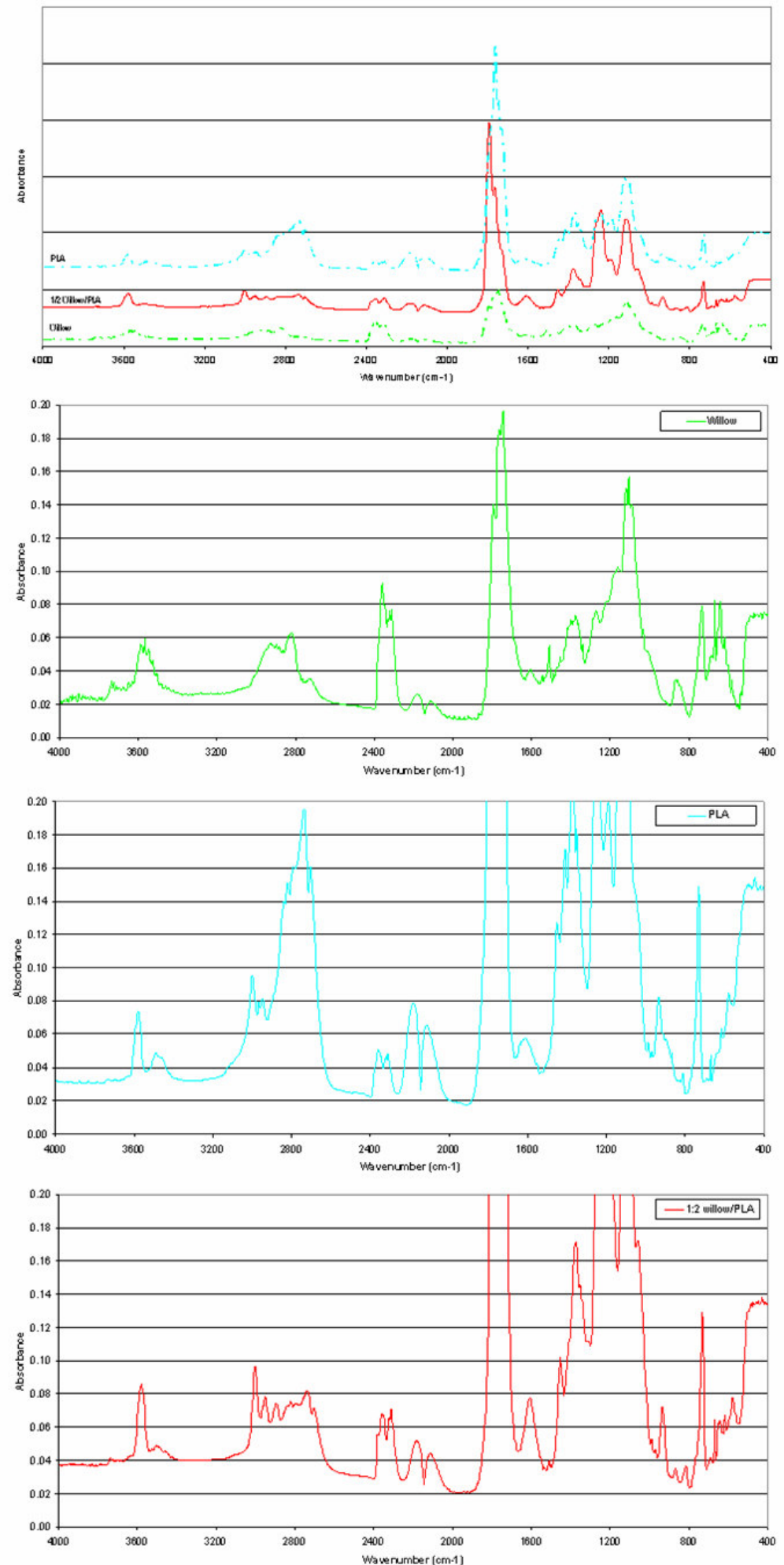

Figure 4: FT-IR spectra of the evolving gases at the maximum decomposition rate during pyrolysis; $a$, overlay; $b$, for willow; c, PLA (scaled up); and d, 1:2 willow/PLA (scaled up), obtained by TG/FTIR. 

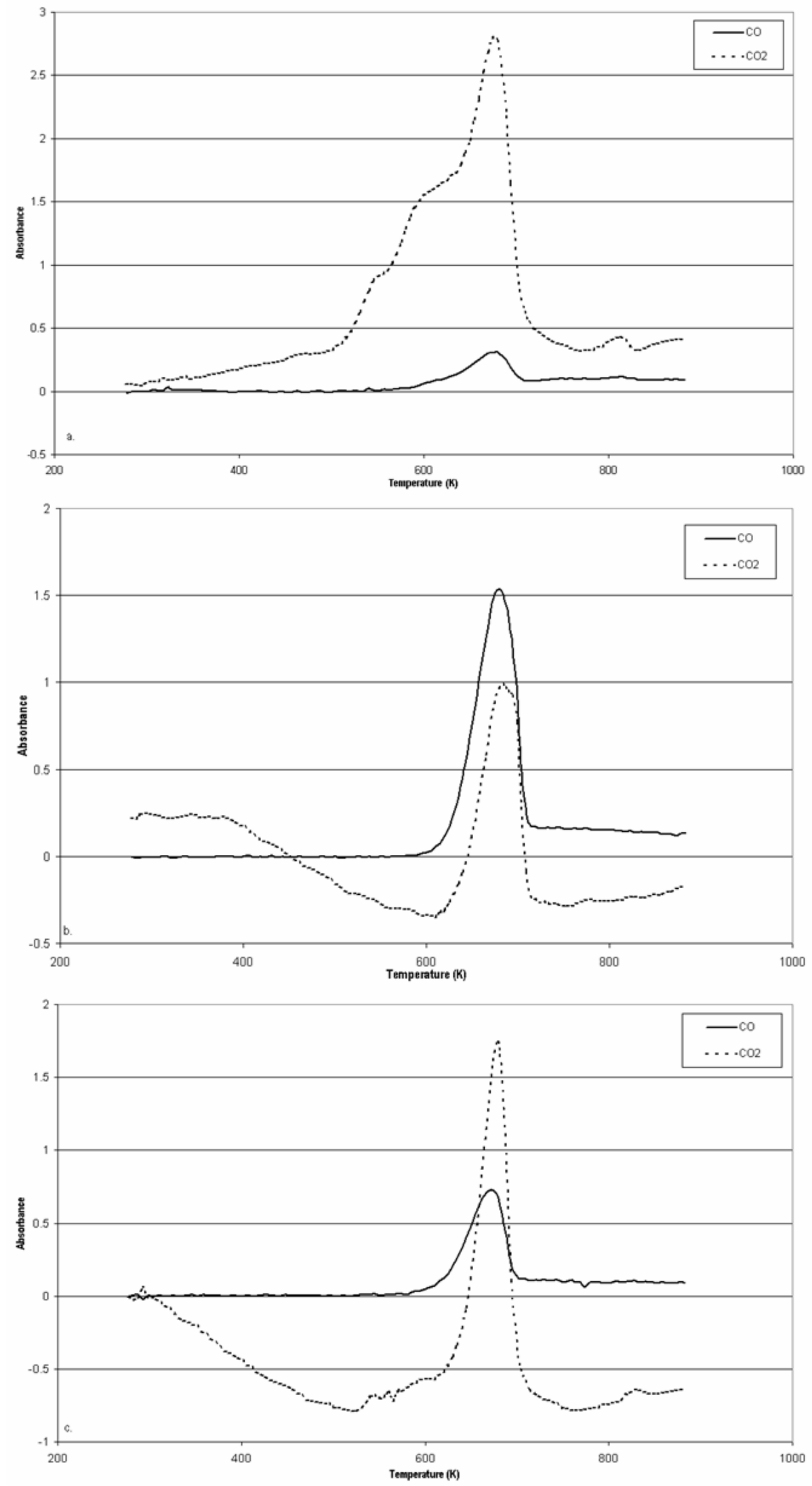

Figure 5: The evolution of $\mathrm{CO}$ and $\mathrm{CO}_{2}$ during the thermal decomposition of a, willow; b, PLA; and c, 1:2 willow/PLA, obtained by TG/FTIR. 
The 3D diagrams in Figure 6, which plot the absorbance $(\mathrm{Y})$ in function of wave number $(\mathrm{X})$ and temperature $(\mathrm{Z})$, obtained by TG/FTIR show that carbonyl functionalities $\left(1650-1860 \mathrm{~cm}^{-1}\right)$ are the most important functionalities in the evolving gases of all three samples during pyrolysis, representing the most abundant peak in the diagrams. Additionally, the evolution of functional groups, expressed as the overall intensity within a specific spectral window, as a function of temperature, has been investigated. Figure 7 shows the evolution of carbonyl functionalities within the $1650-1860 \mathrm{~cm}^{-1}$ range, and of esters and $-\mathrm{C}-\mathrm{O}-$ stretching within the $950-1500 \mathrm{~cm}^{-1}$ range. With regard to the carbonyl functionalities (Figure 7 - a), the most abundant peak is obtained from PLA, and the least abundant from willow, while the $1: 2$ blend is situated somewhere inbetween. The same observation is made for methane and is expected to occur for all functionalities. However, in case of the esters and $-\mathrm{C}-\mathrm{O}$ stretching range the 1:2 willow/PLA blend seems to represent the most abundant peak (Figure $7-b$ ). This observation confirms that additional reactions take place during co-pyrolysis of willow and PLA, resulting in an altered gas composition. Moreover, Figure 7 also indicates that the start of the decomposition of the blend is shifted towards higher temperatures compared to pure willow.

Due to the fact that biomass, and more specifically willow, decomposes in three stages, some possible general reactions can be proposed: 1 . the decomposition of lignine and/or hemicellulose results in volatiles which react with PLA, which on its turn can additionally react with cellulose; 2 . the decomposition of willow (cellulose, hemicellulose and/or lignin) and PLA takes place simultaneously, resulting in 2.a. interactions during the decomposition of willow and PLA and/or 2.b. interactions between volatiles after decomposition of willow and PLA and/or 2.c. interactions between condensables of willow and PLA. 

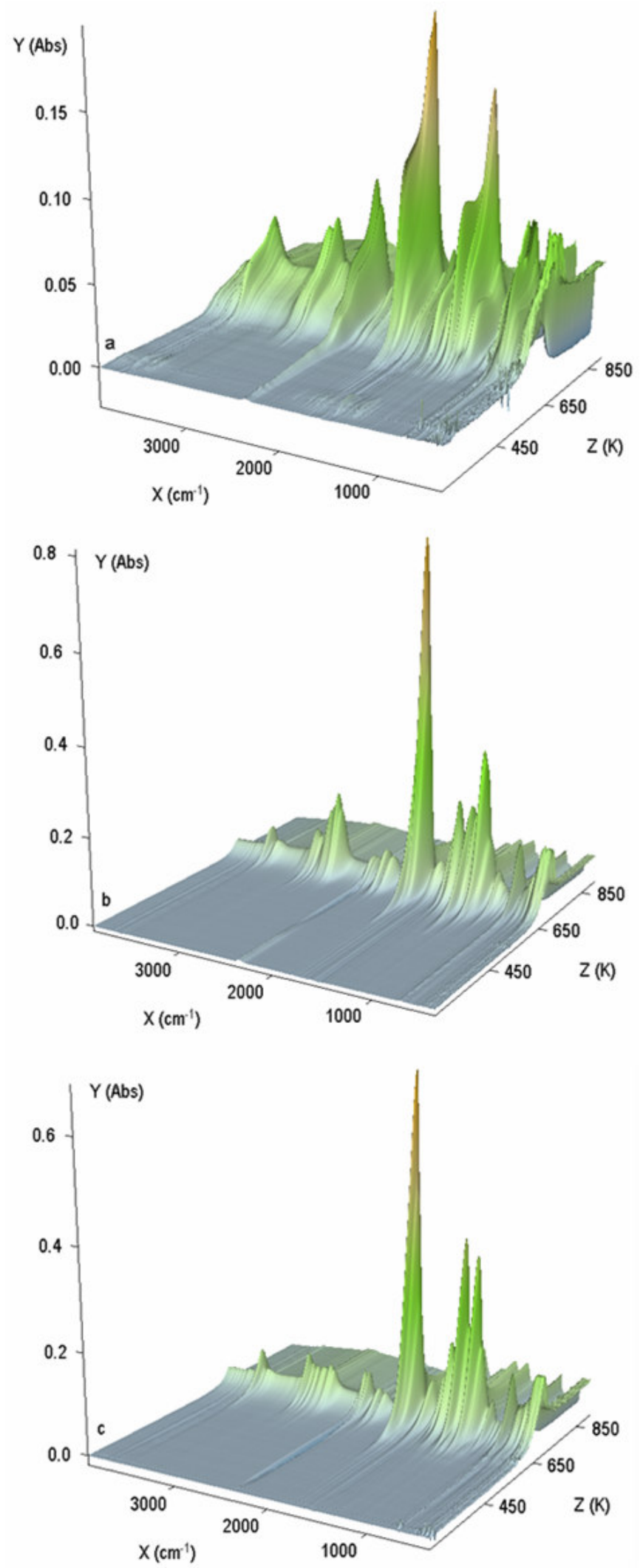

Figure 6: 3D diagrams of a, willow; b, PLA; and c, 1:2 willow/PLA with X: Wave number $\left(\mathrm{cm}^{-1}\right)$; Y: Absorbance Units (Abs); Z: Temperature (K), obtained by TG/FTIR. 

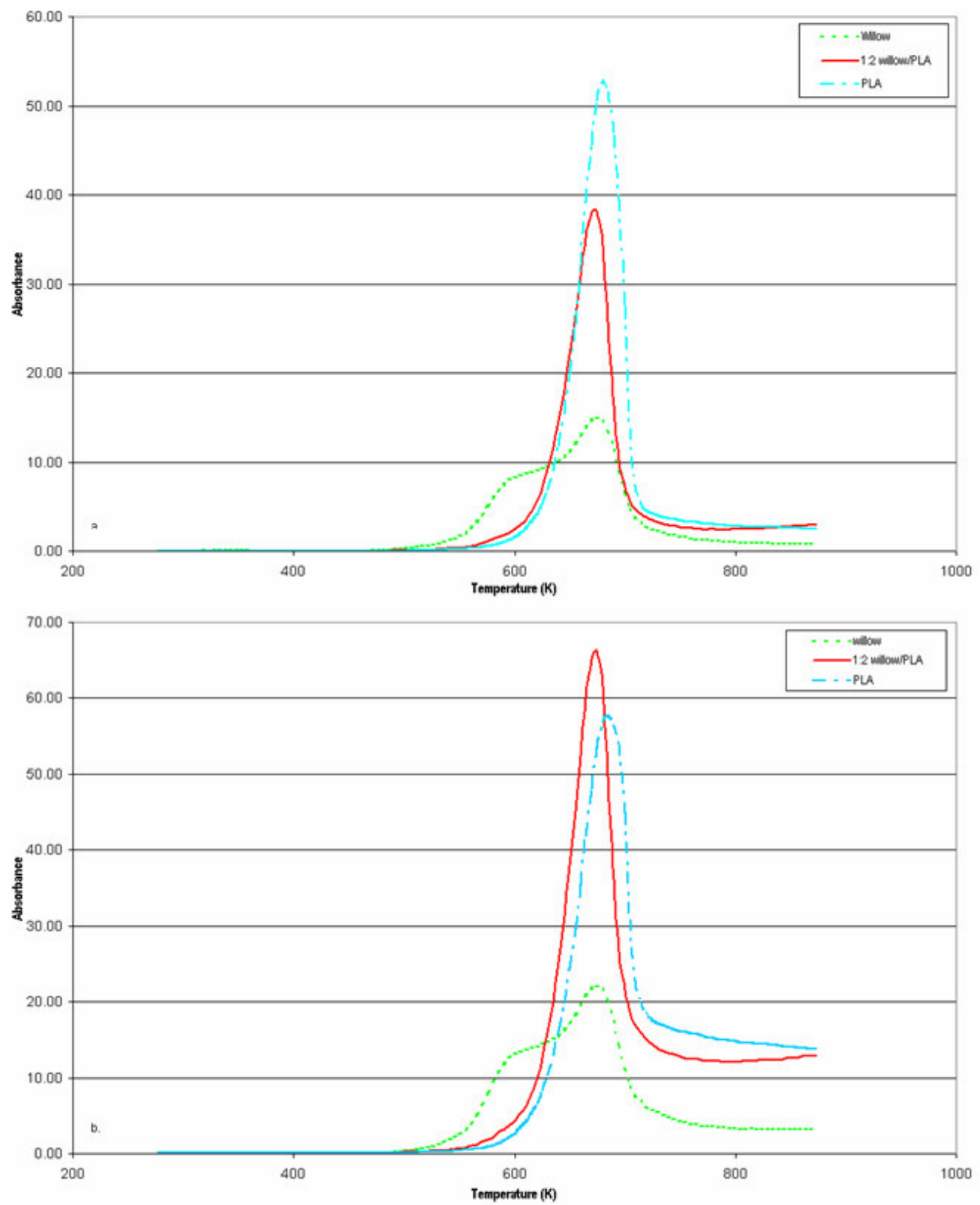

Figure 7: Traces of a, carbonyl functionalities; and b, esters and -C-O- stretching; for willow, PLA, and 1:2 willow/PLA, obtained by TG/FTIR.

Based on the above observations and the proposed reaction mechanisms, flash pyrolysis is performed at $723 \mathrm{~K}$ on pure willow, pure PLA, and 4 different w/w ratios $(10: 1,3: 1,1: 1$ and 1:2) of willow/PLAblends. Table 2 gives a brief summary of the pyrolysis yields and efficiencies of the bio-oil, char and gas productions. The amount of gases is calculated by difference. In Table 3 a subdivision of bio-oil into water-free bio-oil and pyrolytic water is made. 
Table 2: Pyrolysis yields and efficiencies of the bio-oil, char and gas productions.

\begin{tabular}{|c|c|c|c|c|c|c|}
\hline & Willow & 10:1 & $\underline{3: 1}$ & $\underline{1: 1}$ & $\underline{1: 2}$ & $\underline{P L A}$ \\
\hline \multicolumn{7}{|l|}{ Input $(m \%)^{*}$} \\
\hline Willow & 100.0 & 91.3 & 75.4 & 51.8 & 34.6 & 0.0 \\
\hline PLA & 0.0 & 8.7 & 24.6 & 48.2 & 65.4 & 100.0 \\
\hline \multicolumn{7}{|l|}{ Output (m\%) } \\
\hline Bio-oil & 48.85 & 50.90 & 52.70 & 51.30 & 55.53 & 40.60 \\
\hline Char & 23.20 & 20.1 & 17.1 & 13.3 & n.a. ${ }^{* *}$ & 1.5 \\
\hline Gases (by diff.) & 27.95 & 29.0 & 30.2 & 35.4 & n.a. ${ }^{* *}$ & 57.9 \\
\hline
\end{tabular}

In Table 2, a first indication towards synergy is observed: the co-pyrolysis of PLA and willow results in a higher bio-oil yield compared to the sum of the fractional experimental values of both inputs. The synergy seems to increase in direct proportion to the addition of PLA. This synergistic effect is confirmed in Table 3, where the production of water-free bio-oil is higher and that of pyrolytic water lower compared to the sum of the fractional experimental values of both inputs. So, the addition of PLA results into an enhanced bio-oil and water-free bio-oil yield, and a lower water content. The lower water content is a result of the more pronounced decrease in the production of pyrolytic water than theoretically would be expected (except for the 10:1 blend).

Table 3: Subdivision of bio-oil into water-free bio-oil and pyrolytic water based upon the water content; obtained out of $100 \mathrm{~g}$ input.

\begin{tabular}{lcccccc} 
& Willow & $\underline{10: 1}$ & $\underline{\underline{3: 1}}$ & $\underline{1: 1}$ & $\underline{\underline{1: 2}}$ & $\underline{\underline{\text { LA }}}$ \\
\hline \hline Bio-oil $(\mathrm{g})$ & 48.85 & 50.90 & 52.70 & 51.30 & 55.53 & 40.60 \\
Water content $(\mathrm{m} \%)$ & 36.46 & 34.1 & 25.6 & 15.5 & 8.3 & 0.8 \\
\hline \hline Water-free bio-oil $(\mathrm{g})$ & $\mathbf{3 1 . 0 4}$ & $\mathbf{3 3 . 5 4}$ & 39.23 & $\mathbf{4 3 . 3 3}$ & $\mathbf{5 0 . 9 3}$ & $\mathbf{4 0 . 2 8}$ \\
Pyrolytic water $(\mathrm{g})$ & 17.81 & 17.36 & 13.47 & 7.97 & 4.60 & 0.32 \\
\hline \hline
\end{tabular}

The synergy reaches its maximum for the 1:2 willow/PLA blend and is observed in two distinct areas:

- firstly, a higher bio-oil yield (Table 2), i.e. + $28 \%$ more bio-oil versus the theoretical valuei, - and secondly, a lower water content (Table 3), i.e. - $37 \%$ less water versus the theoretical valueii.

\footnotetext{
i The theoretical bio-oil yield $=[(34.6 \mathrm{~g} \times 48.85 \%+65.4 \mathrm{~g} \times 40.60 \%) / 100]=43.45 \mathrm{~m} \%$, while the actual bio-oil yield is 55.53 $\mathrm{m} \%$, thus an increase of $12.08 \mathrm{~m} \%$ or $[(12.08 * 100) / 43.45]=+27.8 \%$.

ii The theoretical water content $=[(34.6 \mathrm{~g} \times 36.46 \%+65.4 \mathrm{~g} \times 0.8 \%) / 100 \%]=13.1 \mathrm{~m} \%$, while the actual water content of the bio-oil is $8.3 \mathrm{~m} \%$, thus a decrease of $4.8 \mathrm{~m} \%$ or $[(-4.8 * 100) / 13.1]=-36.8 \%$.
} 
Incorporating both observations in view of the water-free bio-oil yield, an increase of $37 \%$ is obtained as a synergetic effect, which is clearly substantial both quantitatively and qualitativelyiii.

The averaged experimental H.H.V.'s obtained by calorimetry are summarised in Table 4 and show a relative standard deviation of maximum $1 \%$. The addition of PLA clearly shows a third advantage, namely an increase in the H.H.V. of bio-oil produced from willow/PLA blends compared to bio-oil of pure willow $(16128 \mathrm{~J} / \mathrm{g}$ to $19697 \mathrm{~J} / \mathrm{g})$. However, bio-oil of pure PLA has the highest H.H.V. (22217 J/g). The main reason for the increase in H.H.V. seems to be the decrease of the water content.

Table 4: H.H.V.'s of input materials and bio-oils in Joule per gram.

\begin{tabular}{clc} 
Sample & & $\underline{\text { HHV }(\mathrm{J} / \mathrm{g})}$ \\
\hline \hline Input & Willow & 19088 \\
& PLA & 18597 \\
\hline \hline Bio-oil & Willow & 16128 \\
& Willow/PLA 10:1 & 16832 \\
& Willow/PLA 3:1 & 17683 \\
& Willow/PLA 1:1 & 18489 \\
& Willow/PLA 1:2 & 19697 \\
& PLA & 22217 \\
\hline \hline "The HHV of the input materials are calculated on dry basis.
\end{tabular}

Taking into account the bio-oil yield, the experimental H.H.V. of the 1:2 willow/PLA bio-oil can be translated into an energy recuperation of $58 \%$ iv, while bio-oils from pure willow and pure PLA show an energy recuperation of only $41 \%$ and $48.5 \%$, respectively. In this case, a synergy of $27 \%$ is calculatedv, making the co-pyrolysis of willow and PLA an energetically and economically attractive route to pursue.

\footnotetext{
iii The theoretical water-free bio-oil yield $=[(34.6 \mathrm{~g} \times 31.04 \%+65.4 \mathrm{~g} \times 40.28 \%) / 100 \%]=37.08 \mathrm{~m} \%$, while the actual water-free bio-oil yield is $50.93 \mathrm{~m} \%$, thus an increase of $13.85 \mathrm{~m} \%$ or $\left[\left(13.85^{*} 100\right) / 37.08\right]=+37.34 \%$.

iv The energy recuperation (in bio-oil) $=[(55.53 \mathrm{~g} \times 19697 \mathrm{~J} / \mathrm{g}) \times 100 /(34.6 \mathrm{~g} \times 19088 \mathrm{~J} / \mathrm{g}+65.4 \mathrm{~g} \times 18597 \mathrm{~J} / \mathrm{g})]=58.28 \%$ for the 1:2 willow/PLA co-pyrolysis.

$\checkmark$ The theoretical energy recuperation $=[(34.6 \mathrm{~g} \times 41.27 \%+65.4 \mathrm{~g} \times 48.50 \%) / 100]=46.00 \%$, while the actual energy recuperation is $58.28 \%$, thus an increase of $12.28 \%$ or $[(12.28 * 100) / 46.00]=+26.7 \%$.
} 


\section{Conclusions}

With the aid of TG, TG/MS and TG/FTIR, the decomposition of the input materials over a broad temperature range is visualised. Besides a reduction in volume of (plastic) waste, different synergistic effects occur during co-pyrolysis. Flash co-pyrolysis of willow and polylactic acid at $723 \mathrm{~K}$ results in an enhanced bio-oil yield with a lower water content and a higher calorific value. The synergistic effects are observed to increase along with the addition of PLA. Based on these conclusions, an appropriate biomass/PLA ratio can be proposed for each biomass. In this case study, the flash co-pyrolysis of $1: 2$ willow/PLA resulted in the most pronounced synergy: an increase of $28 \%$ in bio-oil yield, a decrease of $37 \%$ in water content, and an increase of $27 \%$ in energy recuperation. 


\section{Acknowledgements}

The authors like to thank Prof. dr. J. Meuldijk for his guidance, M. Vanhamel for her help with the TG/FTIR analysis, and J. Kaelen for his dedicated contribution in the construction of the semicontinuous home-built pyrolysis installation. This work fits into an association bursary between Xios and University Hasselt. 


\section{References}

[1] European Commission. Towards a European strategy for the security of energy supply. Green Paper 2000; 1-111.

[2] Demirbas A, Arin G. An overview of Biomass pyrolysis. Energy Sources 2002; 24:471-82.

[3] Babu BV, Chaurasia AS. Modeling, simulation and estimation of optimum parameters in pyrolysis of biomass. Energy Conv. Manag. 2003; 44:2135-58.

[4] Onay O, Kockar OM. Slow, fast and flash pyrolysis of rapeseed. Renew. Energy 2003; 28:241733.

[5] Yaman S. Pyrolysis of biomass to produce fuels and chemical feedstocks. Energy Conv. Manag. 2004; 45:651-71.

[6] Bridgwater AV, Meier D, Radlein D. An overview of fast pyrolysis of biomass. Org. Geochem. $1999 ; 30: 1479-93$

[7] Czernik S, Bridgwater AV. Applications of biomass fast pyrolysis oil. In: Bridgwater AV, editor. Fast Pyrolysis of Biomass: A Handbook Volume 3, United Kingdom: CPL Press. 2005; 105-20.

[8] Czernik S, Bridgwater AV. Overview of applications of biomass fast pyrolysis oil. Energy Fuels $2004 ; 18: 590-8$.

[9] Oasmaa A, Meier D. Characterisation, analysis, norms and standards. In: Bridgwater AV, editor. Fast Pyrolysis of Biomass: A Handbook Volume 3, United Kingdom: CPL Press. 2005; 19-59.

[10] Ingemarsson A, Nilsson M, Pedersen JR, Olsson JO. Slow pyrolysis of willow (Salix) studied with GC MS and GC/FTIR/FID. Chemosphere 1999; 39:103-12.

[11] Meszaros E, Jakab E, Varhegyi G, Szepesvary P, Marosvolgyi B. Comparative study of the thermal behavior of wood and bark of young shoots obtained from an energy plantation. J. Anal. Appl. Pyrolysis 2004; 72:317-28. 
[12] Prins MJ, Ptasinski KJ, Janssen F. Torrefaction of wood - Part 1. Weight loss kinetics. J. Anal. Appl. Pyrolysis 2006; 77:28-34.

[13] Prins MJ, Ptasinski KJ, Janssen F. Torrefaction of wood - Part 2. Analysis of products. J. Anal. Appl. Pyrolysis 2006; 77:35-40.

[14] Sharypov VI, Marin N, Beregovtsova NG, Baryshnikov SV, Kuznetsov BN, Cebolla VL, et al. Co-pyrolysis of wood biomass and synthetic polymer mixtures. Part 1: influence of experimental conditions on the evolution of solids, liquids and gases. J. Anal. Appl. Pyrolysis 2002; 64:15-28.

[15] Marin N, Collura S, Sharypov VI, Beregovtsova NG, Baryshnikov SV, Kutnetzov BN, et al. Copyrolysis of wood biomass and synthetic polymers mixtures. Part II: characterisation of the liquid phases. J. Anal. Appl. Pyrolysis 2002; 65:41-55.

[16] Sharypov VI, Beregovtsova NG, Kuznetsov BN, Membrado L, Cebolla VL, Marin N, et al. Copyrolysis of wood biomass and synthetic polymers mixtures. Part III: Characterisation of heavy products. J. Anal. Appl. Pyrolysis 2003; 67:325-40.

[17] Sharypov VI, Beregovtsova NG, Kuznetsov BN, Baryshnikov SV, Cebolla VL, Weber JV, et al. Co-pyrolysis of wood biomass and synthetic polymers mixtures - Part IV: Catalytic pyrolysis of pine wood and polyolefinic polymers mixtures in hydrogen atmosphere. J. Anal. Appl. Pyrolysis $2006 ; 76: 265-70$.

[18] Petrie EM. Biodegradable polymers in adhesive systems. Adhesives \& Sealants 2006; 1-5.

[19] McNeill IC, Leiper HA. Degradation Studies of Some Polyesters and Polycarbonates .2. Polylactide - Degradation under Isothermal Conditions, Thermal-Degradation Mechanism and Photolysis of the Polymer. Polym. Degrad. Stabil. 1985; 11:309-26.

[20] Kopinke FD, Remmler M, Mackenzie K, Moder M, Wachsen O. Thermal decomposition of biodegradable polyesters .2. Poly(lactic acid). Polym. Degrad. Stabil. 1996; 53:329-42.

[21] Kopinke FD, Mackenzie K. Mechanistic aspects of the thermal degradation of poly(lactic acid) and poly(beta-hydroxybutyric acid). J. Anal. Appl. Pyrolysis 1997; 40-1:43-53. 
[22] Westphal C, Perrot C, Karlsson S. Py-GC/MS as a means to predict degree of degradation by giving microstructural changes modelled on LDPE and PLA. Polym. Degrad. Stabil. 2001; 73:281-7.

[23] Tsamba AJ, Yang WH, Blasiak W. Pyrolysis characteristics and global kinetics of coconut and cashew nut shells. Fuel Process. Technol. 2006; 87:523-30. 